\title{
Acquired Central Hypothyroidism
}

National Cancer Institute

\section{Source}

National Cancer Institute. Acquired Central Hypothyroidism. NCI Thesaurus. Code C120442.

Central hypothyroidism, the cause of which is not present at birth. 